\title{
All-trans-retinoic acid inhibits tumour growth of malignant pleural mesothelioma in mice
}

\author{
C. Tabata*, R. Tabata\#, N. Hirayama*, A. Yasumitsu*, S. Yamada*, A. Murakami*, \\ S. lida*, K. Tamura*, T. Terada*, K. Kuribayashi*, K. Fukuoka* and T. Nakano*
}

ABSTRACT: Malignant pleural mesothelioma (MPM) is an aggressive malignant tumour of mesothelial origin associated with asbestos exposure. Because MPM has limited response to conventional chemotherapy and radiotherapy, the prognosis is very poor. Several researchers have reported that cytokines such as interleukin (IL)-6 play an important role in the growth of MPM. Previously, it was reported that all-trans-retinoic acid (ATRA) inhibited the production and function of IL- 6 and transforming growth factor (TGF)- $\beta 1$ in experiments using lung fibroblasts.

We investigated whether ATRA had an inhibitory effect on the cell growth of MPM, the origin of which was mesenchymal cells similar to lung fibroblasts, using a subcutaneous xenograft mouse model. We estimated the tumour growth and performed quantitative measurements of IL-6, TGF$\beta 1$ and platelet-derived growth factor (PDGF) receptor (PDGFR)- $\beta$ mRNA levels both of cultured MPM cells and cells grown in mice with or without the administration of ATRA.

ATRA significantly inhibited MPM tumour growth. In vitro studies disclosed that the administration of ATRA reduced 1) mRNA levels of TGF- $\beta 1$, TGF- $\beta 1$ receptors and PDGFR- $\beta$, and 2) TGF- $\beta 1$-dependent proliferation and PDGF-BB-dependent migration of MPM cells.

These data may provide a rationale to explore the clinical use of ATRA for the treatment of MPM.

\section{KEYWORDS: Cytokines, mesothelioma}

M alignant pleural mesothelioma (MPM) is an aggressive malignant tumour of mesothelial origin associated with asbestos exposure [1]. Although recently asbestos usage has decreased throughout the world, the incidence of MPM is expected to markedly increase over the next few decades because there is a long latency period (20-40 yrs) between asbestos exposure and tumour development [2]. MPM has limited response to conventional chemotherapy and radiotherapy, so the prognosis is very poor, with median survival durations of 8-18 months [3]. Despite much research into MPM treatment, there has been little progress in effective therapeutic and preventive strategies against MPM, and the development of novel treatment is urgently needed [4].

According to recent research investigating cytokines in relation to MPM, several cytokines, such as interleukin (IL)-6 [5] and hepatocyte growth factor/scatter factor [6], play an important role in the growth of MPM.

All-trans-retinoic acid (ATRA), a physiological metabolite of vitamin $\mathrm{A}$, is known to affect cell differentiation, proliferation and development. ATRA has been widely used in differentiation therapy for acute promyelocytic leukaemia (APL) with the ability to overcome promyelocytic leukaemia/retinoic acid receptor fusion protein There have been several reports about the effects of ATRA on cytokine production [7-9]. ATRA induced the growth inhibition of myeloma cells, which proliferated in IL-6 autocrine and paracrine manners, with the reduction of both IL-6 production and its receptor (IL-6R) expression [10, 11]. In a previous report, it was demonstrated that ATRA reduced irradiation-induced proliferation of lung fibroblasts by inhibiting both IL- 6 production and IL-6R expression [12]. Moreover, it was recently reported that ATRA prevented both irradiationand bleomycin-induced pulmonary fibrosis in mice via an inhibitory effect on both IL-6dependent fibroblast proliferation and transforming growth factor (TGF)- $\beta 1$-dependent transdifferentiation of fibroblasts into myofibroblasts [13]

In the present study, we investigated whether ATRA had an inhibitory effect on the cell growth of MPM, the origin of which was mesenchymal cells similar to lung fibroblasts and associated with several cytokines, including IL-6.

\section{METHODS}

\section{Cell culture}

Human MPM cell lines H28 (epithelioid), H2052 (sarcomatoid), H2452 (biphasic) and MSTO-211H

\section{AFFILIATIONS}

*Division of Respiratory Medicine Dept of Internal Medicine, Hyogo College of Medicine, Nishinomiya and

\#Dept of Internal Medicine, Hyogo Prefectural Tsukaguchi Hospital, Amagasaki, Japan.

CORRESPONDENCE

C. Tabata

Division of Respiratory Medicine, Dept of Internal Medicine Hyogo College of Medicine 1-1 Mukogawa-cho Nishinomiya

Hyogo 663-8501 Japan E-mail: ctabata@hyo-med.ac.jp

Received:

Dec 242008

Accepted after revision: April 082009 First published online: May 142009 
(biphasic) and human mesothelial cell line MeT-5A were obtained from the American Type Culture Collection (Rockville, MD, USA). These cells were cultured in RPMI 1640 (Sigma Chemical Co., St Louis, MO, USA) supplemented with $10 \%$ heat-inactivated fetal calf serum. ATRA (Sigma) was added to the growth medium to yield the final dimethyl sulfoxide (DMSO) solvent concentration $<0.05 \%(v / v)$. In some experiments, the cells were pre-incubated with proteasome inhibitor MG-132 (5 $\mu \mathrm{M})$ [14], Jun N-terminal kinase (JNK) inhibitor SP600125 $(10 \mu \mathrm{M})$ [15], p38 mitogen-activated protein kinase (MAPK) inhibitor SB203580 (10 $\mu \mathrm{M})$ [16] or extracellular signalregulated kinase (ERK)1/2 inhibitor PD98059 (25 $\mu \mathrm{M})$ [13] for 60 min (all Calbiochem, San Diego, CA, USA).

\section{Animals}

6-week-old C.B-17/Icr-scid Jcl (scid/scid) (SCID) female mice were purchased from Clea Japan (Tokyo, Japan) and maintained in our specific pathogen-free animal facility. All animals were kept according to the Animal Protection Guidelines of Hyogo College of Medicine (Hyogo, Japan). All protocols for animal use and euthanasia were reviewed and approved by the Institute of Laboratory Animals, Graduate School of Medicine, Hyogo College of Medicine.

\section{Ectopic (subcutaneous) xenograft model}

To produce subcutaneous (s.c.) tumours, a single-cell suspension of $10^{7}$ MSTO- $211 \mathrm{H}$ cells was implanted s.c. into the back of SCID mice. In some experiments, mice were injected intraperitoneally with $0.5 \mathrm{mg}$ of ATRA dissolved in $0.1 \mathrm{~mL}$ cottonseed oil or with $0.1 \mathrm{~mL}$ cottonseed oil alone (controls). Injections were repeated three times weekly, 1) throughout the course, or 2) in the latter half of the period from inoculation to the end of the observation period. In previous studies, $0.5 \mathrm{mg}$ of ATRA administration three times per week for 6 months did not produce noticeable morbidity and mortality [12, 13]. The tumours were measured every 7 days with calipers, and their volumes were calculated using the formula $a\left(b^{2}\right) / 2$, in which a and $b$ represent the longest and shortest diameters, respectively.

\section{Quantitative real-time reverse transcriptase PCR}

Total RNA was isolated by RNeasy Mini kit (QIAGEN, Valencia, CA, USA), and reverse-transcribed by High Capacity cDNA Reverse Transcription Kit (Applied Biosystems, Foster City, CA, USA). Quantitative real-time reverse transcriptase (RT)-PCR was performed as previously described [12, 13], using TaqMan Gene expression products for human IL-6, IL-6R, TGF$\beta 1$, TGF- $\beta 1$ receptor (TGF- $\beta 1 \mathrm{R}$ ) type 1 , TGF- $\beta 1 \mathrm{R}$ type 2 , plateletderived growth factor (PDGF)- $\beta$, PDGF receptor (PDGFR)- $\beta$ and cytochrome gene CYP26A1. 18S ribosomal (r)RNA served as an endogenous control (Applied Biosystems).

\section{Measurement of nuclear factor-kB p65, p38MAPK and JNK}

Nuclear extracts were prepared and protein concentration in nuclear extracts was measured as previously described [12]. Nuclear factor (NF)- $\mathrm{B}$ p65, cytoplasmic phospho-p38MAPK $\left(\mathrm{pThr}^{180} / \mathrm{pThr}^{182}\right.$ ) and cytoplasmic JNK were detected by ELISA Kit (BioSource (Camarillo, CA, USA), Sigma and Active Motif (Carlsbad, CA, USA), respectively).

\section{Cell proliferation assay}

Cell proliferation assays were performed as previously described [12]. Cells were cultured in 96-well flat-bottomed culture plates for 2 days with or without TGF- $\beta 1\left(1-10,000 \mathrm{pg} \cdot \mathrm{mL}^{-1}\right)$, and/or ATRA $\left(10^{-5} \mathrm{M}\right)$.

\section{Cell migration assay}

In vitro migration assays were performed by CytoSelect 24-well Cell Migration Assay $(8 \mu \mathrm{m}$, Colorimetric Format; CELL BIOLABS, Huissen, the Netherlands), according to the manufacturer's instructions. Briefly, MSTO-211H cells were precultured overnight with or without ATRA $\left(10^{-5} \mathrm{M}\right)$ and were then suspended at a density of $1 \times 10^{6} \mathrm{cells} \cdot \mathrm{mL}^{-1}$ in RPMI 1640 and placed in the upper half of the Boyden chamber. The lower half of the Boyden chamber was filled with RPMI 1640 containing $10 \mathrm{ng} \cdot \mathrm{mL}^{-1}$ human recombinant PDGF-BB (PeproTech, London, UK) or RPMI 1640 alone.

\section{Analysis of apoptosis}

MPM cells undergoing apoptosis were detected in tissue sections by the terminal deoxynucleotidyl transferasemediated deoxyuridine triphosphate-biotin nick-end labelling (TUNEL) method, using the in situ apoptosis detection TUNEL kit (Takara, Shiga, Japan) according to the manufacturer's instructions.

\section{Statistical analysis}

The results are given as the mean $\pm \mathrm{SD}$ of three experiments performed in triplicate. Statistical analysis was performed using the Bonferroni/Dunn multiple comparisons test. In all tests, a p-value $<0.05$ was considered significant.

\section{RESULTS}

Inhibitory effect of ATRA on proliferation of MPM cells

We first investigated the effect of ATRA on the growth of both MPM (H28, H2052, H2452 and MSTO-211H) and mesothelial (MeT-5A) cells. Cells were cultured with or without various concentrations of ATRA for $48 \mathrm{~h}$. The addition of ATRA had a suppressive effect on the proliferation of all of these MPM cells in a dose-dependent manner. The maximum inhibitory effect was observed at the concentration of $10^{-5} \mathrm{M}$ ATRA (H28: 59\% decrease ( $p<0.0001)$; H2042: 33\% decrease ( $<<0.0001)$; H2452: $45 \%$ decrease $(\mathrm{p}<0.0001) ; \quad$ MSTO-211H: $29 \%$ decrease $(\mathrm{p}<0.0001)$ ) (fig. 1a-d), whereas the lower concentrations $\left(10^{-7} \mathrm{M}\right.$ or $\left.10^{-6} \mathrm{M}\right)$ of ATRA showed a minor effect compared with $10^{-5} \mathrm{M}$. Conversely, ATRA had no effect on the proliferation of MeT-5A (fig. 1e). The final concentration of DMSO $(0.05 \% \mathrm{v} / \mathrm{v})$ had no gross effect on any cells (data not shown). The concentration of $10^{-5} \mathrm{M}$ ATRA had no effect on cell viabilities in any cell lines (data not shown).

\section{Effect of ATRA on TGF- $\beta 1 /$ TGF- $\beta 1 R$ mRNA expression of MPM cells}

As shown in figure $2 \mathrm{a}$, the TGF- $\beta 1$ mRNA as a ratio of $18 \mathrm{~S}$ rRNA expression was decreased following $7 \mathrm{~h}$ of culture with $10^{-5} \mathrm{M}$ ATRA: by $29 \%$ in $\mathrm{H} 28$ ( $<<0.0001)$, by $47 \%$ in $\mathrm{H} 2052$ ( $\mathrm{p}=0.0002)$, by $38 \%$ in $\mathrm{H} 2452(\mathrm{p}=0.0002)$ and by $56 \%$ in MASTO- $211 \mathrm{H}$ cells $(\mathrm{p}<0.0001)$, compared with cells incubated with DMSO alone. Conversely, ATRA had no effect on TGF- $\beta 1$ mRNA expression in MeT-5A mesothelial cells. Both TGF- $\beta 1 \mathrm{R}$ type 1 and type 2 mRNA/18S rRNA ratios were also decreased with ATRA 
a) $\mathrm{H} 28$

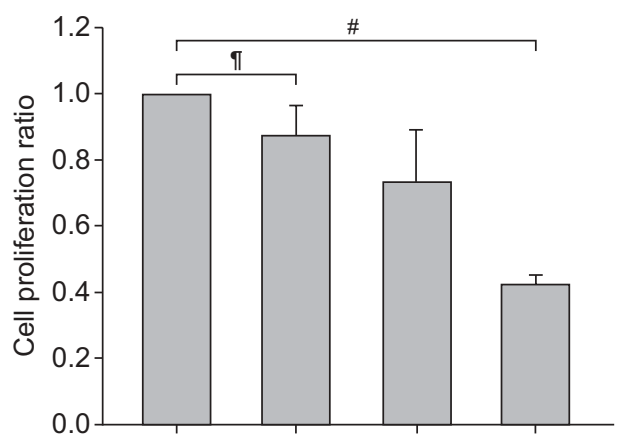

d) MSTO-211H

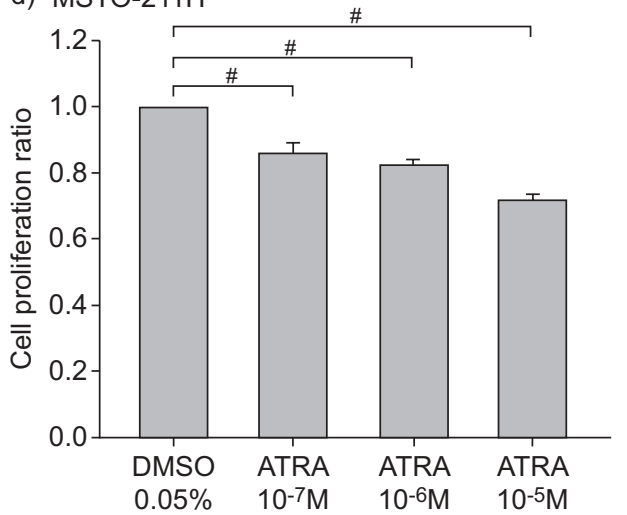

b) $\mathrm{H} 2052$

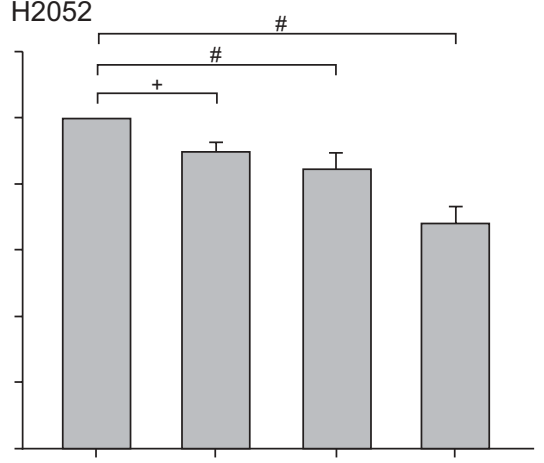

e) MeT-5A

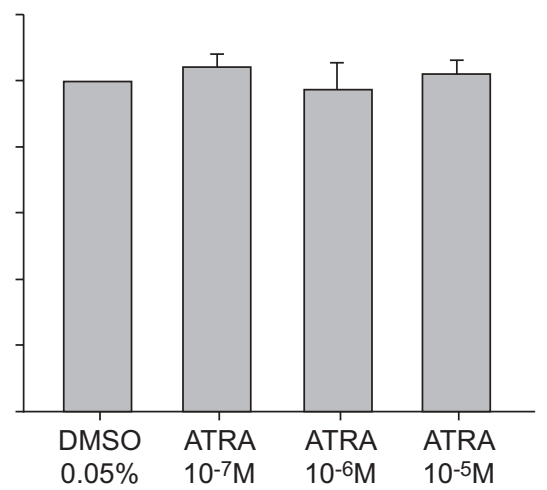

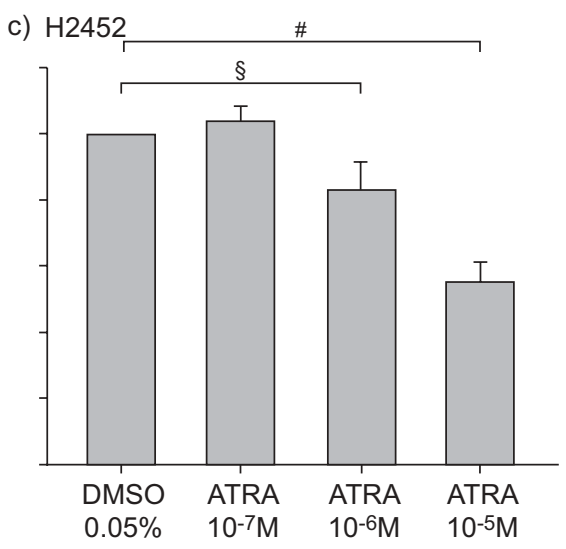

FIGURE 1. Inhibitory effect of all-trans-retinoic acid (ATRA) on proliferation of malignant pleural mesothelioma (MPM) cells. a) H28, b) H2052, c) H2452 and d) MSTO$211 \mathrm{H}$ MPM cells and e) human mesothelial cell line MeT-5A were cultured in 96-well flat-bottomed culture plates for $48 \mathrm{~h}$ in serum-free medium with or without (dimethyl sulfoxide (DMSO) alone) various concentrations $\left(10^{-7}, 10^{-6}\right.$ or $\left.10^{-5} \mathrm{M}\right)$ of ATRA, and cell proliferation was assayed. The results are indicated as the mean $\pm \mathrm{SD}$ of three

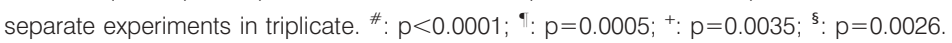

compared with cells incubated with DMSO alone (type 1: 19\% in $\mathrm{H} 28(\mathrm{p}=0.0023), 22 \%$ in $\mathrm{H} 2052(\mathrm{p}<0.0001), 29 \%$ in $\mathrm{H} 2452$ $(\mathrm{p}<0.0001)$ and $42 \%$ in MSTO-211H $(\mathrm{p}<0.0001)$; type $2: 48 \%$ in $\mathrm{H} 28(\mathrm{p}<0.0001), 27 \%$ in H2052 $(\mathrm{p}=0.0003), 43 \%$ in $\mathrm{H} 2452$ $(\mathrm{p}<0.0001)$ and $57 \%$ in MSTO-211H $(\mathrm{p}<0.0001)$. Conversely, ATRA had no effect on TGF- $\beta 1 R$ type 1 and type 2 mRNA expression in MeT-5A (fig. $2 \mathrm{~b}$ and $\mathrm{c}$ ).

\section{Involvement of NF- $\kappa B$ in the suppressive effect of ATRA on TGF- $\beta 1$ mRNA expression}

Proteasome inhibitor MG-132 is also known to have an inhibitory effect on NF- $\mathrm{BB}$ activity. Pretreatment of MPM cells with MG-132 led to decreased TGF- $\beta 1$ mRNA levels by $47 \%$ in $\mathrm{H} 28(\mathrm{p}<0.0001), 68 \%$ in $\mathrm{H} 2052(\mathrm{p}<0.0001), 60 \%$ in $\mathrm{H} 2452$ $(\mathrm{p}<0.0001)$ and $75 \%$ in MSTO-211H $(\mathrm{p}<0.0001)$ compared with cells incubated with DMSO alone (fig. 3a). Next, we demonstrated that the levels of nuclear NF- $\mathrm{B}$ p65 in these cells were suppressed in the presence of ATRA by $11 \%$ in H28 ( $\mathrm{p}=$ $0.0162), 13 \%$ in $\mathrm{H} 2052$ ( $\mathrm{p}=0.018), 10 \%$ in $\mathrm{H} 2452$ ( $\mathrm{p}=0.0302)$ and $14 \%$ in MSTO- $211 \mathrm{H}(\mathrm{p}=0.0012)$ compared with cells incubated with DMSO alone (fig. 3b). Although pretreatment with inhibitors for both p38MAPK and JNK led to decreased TGF$\beta 1 \mathrm{mRNA}$ levels in these cells, the level of phospho-p38MAPK and activity of JNK were not affected by ATRA (data not shown). Inhibitors of ERK1/2 had no effect on TGF- $\beta 1$ mRNA levels (data not shown).

\section{Effect of ATRA on TGF- $\beta 1$-mediated proliferation of MPM cells}

To clarify the involvement of TGF- $\beta 1$ in the development of MPM tumour growth, we studied the effect of TGF- $\beta 1$ on the proliferation of MPM cells and MeT-5A mesothelial cells. As shown in figure $4 \mathrm{a}$, the addition of TGF- $\beta 1$ stimulated all MPM cell growth in a dose-dependent manner and reached a plateau at the concentration of $1,000 \mathrm{pg} \cdot \mathrm{mL}^{-1}(\mathrm{H} 28: 18 \%$ increase $(\mathrm{p}=0.0012) ; \mathrm{H} 2042: 19 \%$ increase $(\mathrm{p}=0.0015) ; \mathrm{H} 2452: 30 \%$ increase $(p<0.0001)$; MSTO-211H: $46 \%$ increase $(p=0.0069))$. Conversely, TGF- $\beta 1$ had no effect on the proliferation of MeT5A mesothelial cells (fig. 4a). We then evaluated the effect of ATRA on TGF- $\beta 1-$ mediated proliferation of MPM cells, and showed that the TGF- $\beta 1$-mediated proliferation was decreased with ATRA by $39 \%$ in H28 $(\mathrm{p}<0.0001), 48 \%$ in $\mathrm{H} 2052$ $(p=0.0013), 80 \%$ in $\mathrm{H} 2452(\mathrm{p}<0.0001)$ and $73 \%$ in MSTO$211 \mathrm{H}(\mathrm{p}<0.0001)$ compared with cells incubated with DMSO alone (fig. $4 b$ ).

\section{Antitumour efficacy of ATRA in a subcutaneous xenograft model}

We next examined the effect of ATRA on a s.c. xenograft mouse model of MPM cells. A single-cell suspension of $10^{7} \mathrm{H} 28$, $\mathrm{H} 2052, \mathrm{H} 2452$ and MSTO-211H cells with a viability of $>95 \%$ was implanted s.c. into the back of SCID mice. Only MSTO$211 \mathrm{H}$ cells could grow on the back of SCID mice. To study the 

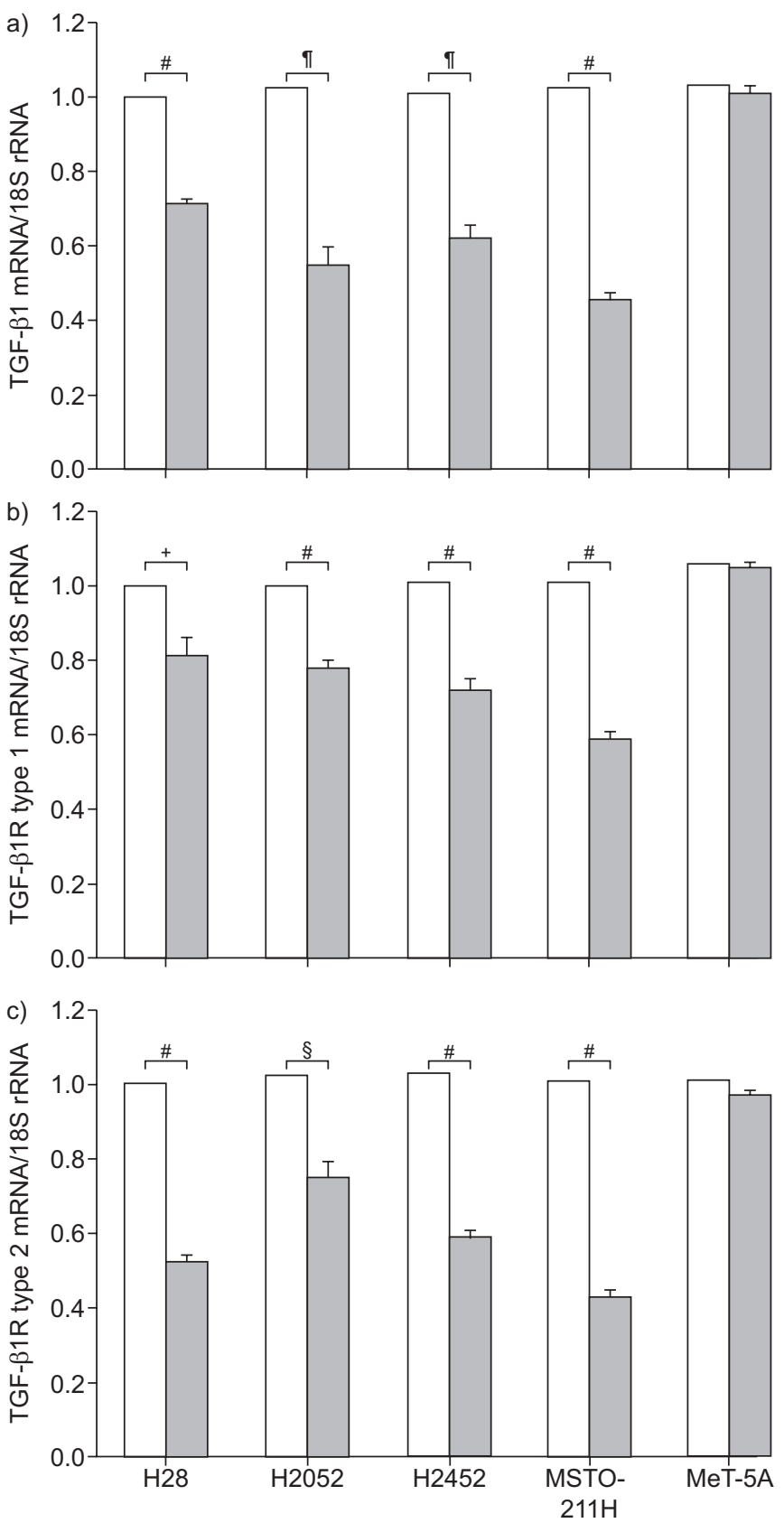

FIGURE 2. Effect of all-trans-retinoic acid (ATRA) on transforming growth factor (TGF)- $\beta 1 / T G F-\beta 1$ receptor (TGF- $\beta 1$ R) mRNA expression of malignant pleural mesothelioma (MPM) cells. Real-time reverse transcriptase PCR was performed to determine the changes in mRNA levels for TGF- $\beta 1 /$ TGF- $\beta 1$ Rs. H28, H2052, H2452 and MSTO-211H MPM cells and the human mesothelial cell line MeT-5A were cultured in the presence ( $\square$ ) or absence (dimethyl sulfoxide (DMSO) alone; $\square$ ) of $10^{-5} \mathrm{M}$ of ATRA for $7 \mathrm{~h}$. The levels of mRNA for a) TGF- $\beta 1, \mathrm{~b}$ ) TGF- $\beta 1 \mathrm{R}$ type 1 and c) TGF- $\beta 1 R$ type 2 are represented as the ratio to $18 \mathrm{~S}$ ribosomal (r)RNA, an endogenous control. The results are indicated as the mean \pm SD of three separate experiments in triplicate. ${ }^{*}: p<0.0001 ; " p=0.0002 ;{ }^{+}: p=0.0023 ;{ }^{s}: p=0.0003$.

"preventive" and "therapeutic" effects of ATRA on MSTO$211 \mathrm{H}$ cell growth, i.p. injections of ATRA were repeated three times weekly, 1) throughout the course, or 2) in the latter half of the period from inoculation to the end of the observation period. As shown in figure 5a, i.p. administration of ATRA
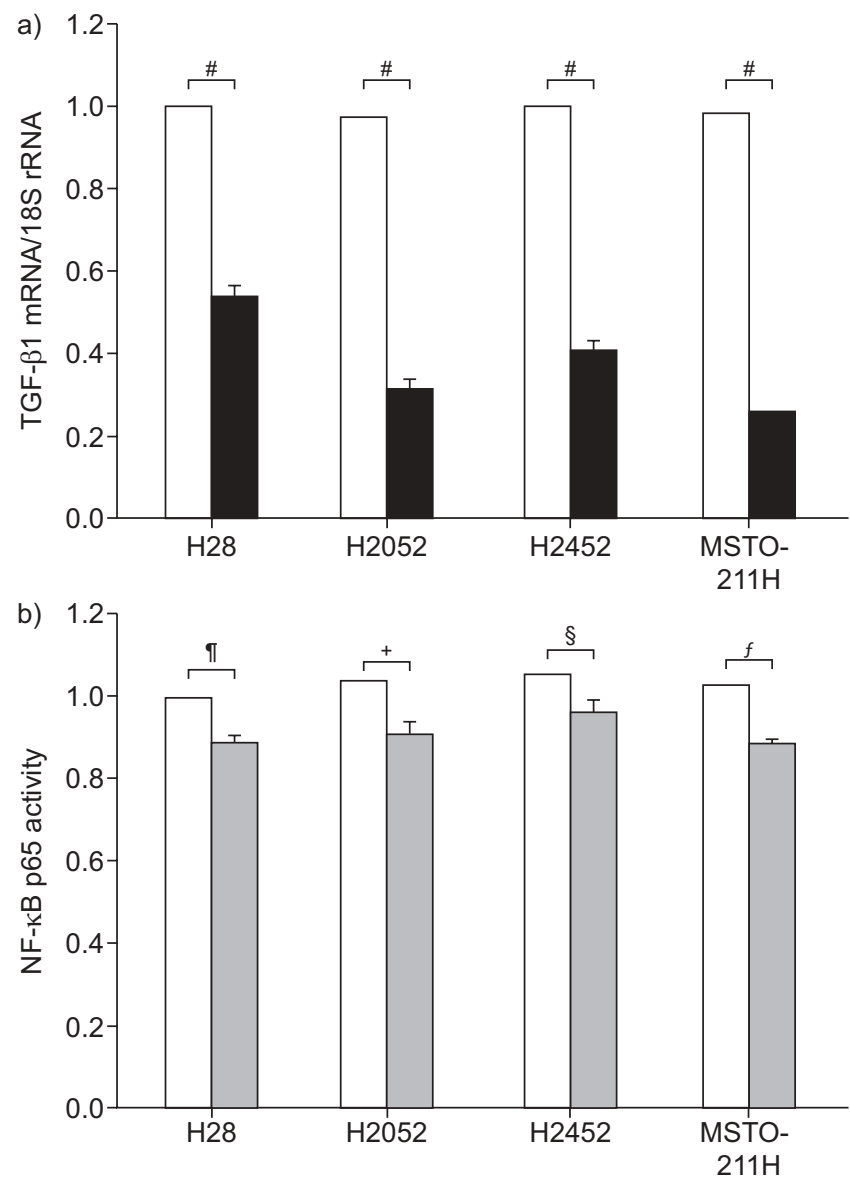

FIGURE 3. Involvement of nuclear factor (NF)-kB in the suppressive effect of all-trans-retinoic acid (ATRA) on transforming growth factor (TGF)- $\beta 1$ mRNA expression. a) H28, H2052, H2452 and MSTO-211H malignant pleural mesothelioma cells were cultured in the presence $(\boldsymbol{\square})$ or absence (dimethyl sulfoxide (DMSO) alone; $\square$ ) of $5 \mu \mathrm{M}$ MG-132 for $7 \mathrm{~h}$. Real-time reverse transcriptase PCR was performed to determine changes in TGF- $\beta 1$ mRNA levels. b) The activities of NF-kB were analysed. H28, H2052, H2452 and MSTO-211H cells were treated with ( $\square$ ) or without (DMSO alone; $\square$ ) ATRA $\left(10^{-5} \mathrm{M}\right)$ for $1 \mathrm{~h}$ and NF-kB p65 amounts in nuclear protein extracts were analysed. The results are indicated as the mean $\pm \mathrm{SD}$ of three separate experiments in triplicate. ${ }^{\#}: p<0.0001 ;{ }^{\top}: p=0.0162 ;{ }^{+}: p=0.018$; s: $p=0.0302 ;{ }^{f}: p=0.0012$.

three times per week throughout the course greatly inhibited tumour growth at 28 days after inoculation (68\% decrease; $\mathrm{p}<0.0001)$. Moreover, treatment with ATRA three times per week for the latter half of the period from inoculation to the end of the observation period ameliorated tumour growth better than the vehicle control group $(36 \%$ decrease; $p=0.0011)$. The i.p. injection with $0.5 \mathrm{mg}$ of ATRA three times a week for 28 days had no effect on the health of the mice.

\section{mRNA levels of TGF- $\beta 1$ and PDGFR- $\beta$ in implanted grown tumours on SCID mice}

TGF- $\beta 1$ mRNA levels of implanted grown MPM tumours on SCID mice at 28 days after inoculation with or without an i.p. injection of ATRA were analysed by real-time RT-PCR. We demonstrate in figure $5 b$ that TGF- $\beta 1$ mRNA expression was significantly suppressed by the administration of ATRA (32\% decrease; $p=0.0008)$. To study whether another mechanism 

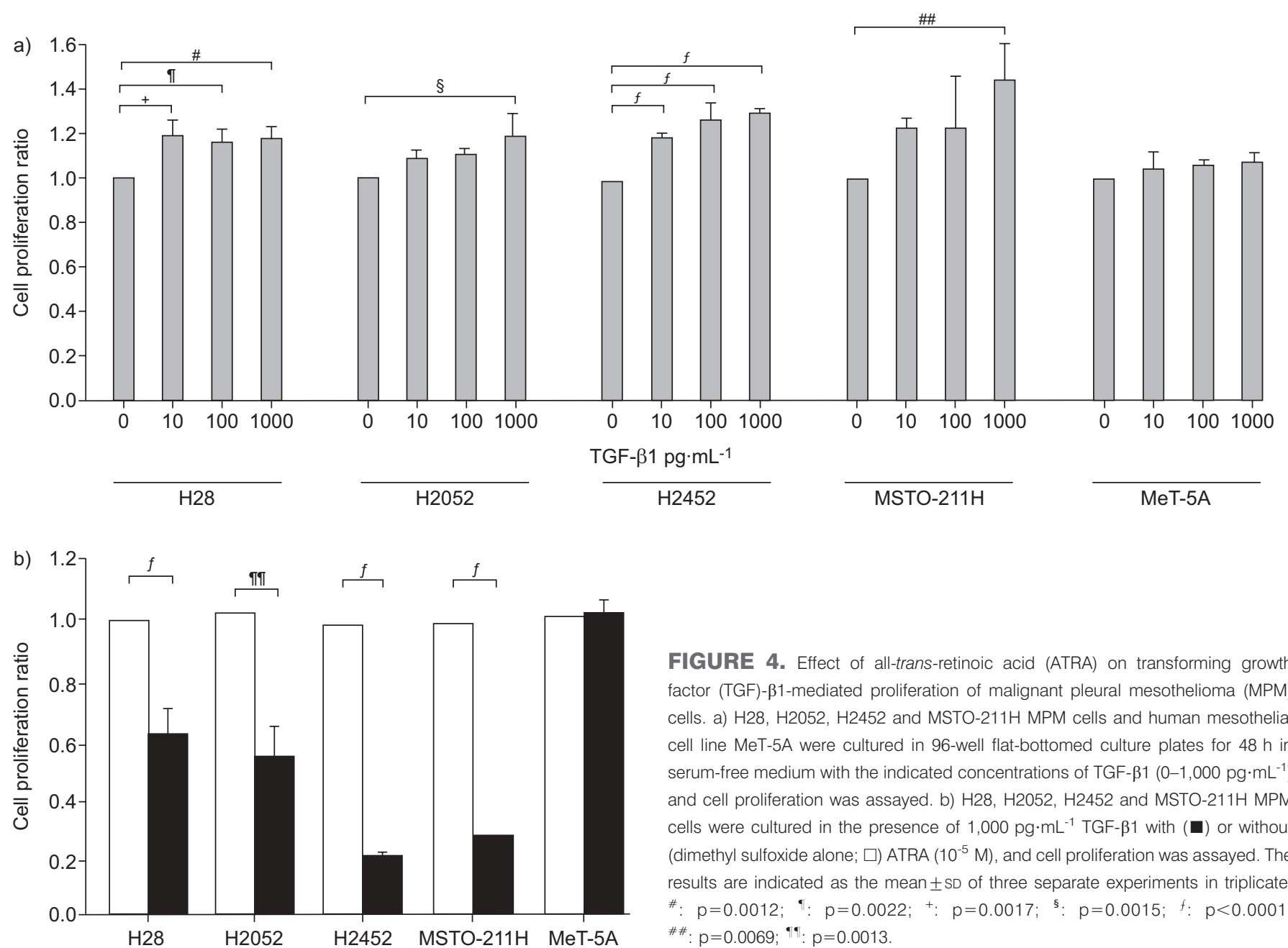

FIGURE 4. Effect of all-trans-retinoic acid (ATRA) on transforming growth factor (TGF)- $\beta 1$-mediated proliferation of malignant pleural mesothelioma (MPM) cells. a) H28, H2052, H2452 and MSTO-211H MPM cells and human mesothelial cell line MeT-5A were cultured in 96-well flat-bottomed culture plates for $48 \mathrm{~h}$ in serum-free medium with the indicated concentrations of TGF- $\beta 1\left(0-1,000 \mathrm{pg} \cdot \mathrm{mL}^{-1}\right)$ and cell proliferation was assayed. b) H28, H2052, H2452 and MSTO-211H MPM cells were cultured in the presence of $1,000 \mathrm{pg} \cdot \mathrm{mL}^{-1} \mathrm{TGF}-\beta 1$ with (ם) or without (dimethyl sulfoxide alone; $\square$ ) ATRA $\left(10^{-5} \mathrm{M}\right)$, and cell proliferation was assayed. The results are indicated as the mean $\pm \mathrm{SD}$ of three separate experiments in triplicate \#: $p=0.0012 ; \quad$ ध: $p=0.0022 ;{ }^{+}: p=0.0017 ;$ \&: $p=0.0015 ;$ f: $p<0.0001$; \#\#: $p=0.0069 ; \%: p=0.0013$.

was involved in the preventive effect of ATRA on MPM tumour progression, we focused on previous reports demonstrating that human mesothelioma cell lines expressed PDGFR- $\beta$ [17]. We then analysed PDGFR- $\beta$ expression in implanted grown MPM tumours and found that, in mice treated with ATRA, the levels of PDGFR- $\beta$ expression were markedly decreased as compared with mice without ATRA ( $31 \%$ decrease; $p=0.0004$; fig. $5 c$ ).

\section{Inhibitory effect of ATRA on PDGFR- $\beta$ expression and PDGF-BB-induced migration of MPM cells}

We next examined the impact of ATRA on PDGFR- $\beta$ mRNA expression in MPM cells. As shown in figure 6a, ATRA decreased the expression of PDGFR- $\beta$ mRNA by $32 \%$ in MSTO-211H cells $(p<0.0001)$; however, ATRA had no effect on the production of PDGF-BB (data not shown). It is well known that cell migration plays an important role in tumour cell invasion, especially in the wide spread of MPM tumours. We therefore performed an in vitro migration assay to study the effect of PDGF, which is a potent mitogen and chemotactic factor for several mesenchymal cells [18], on MPM progression, and revealed that MSTO-211H cell migration was induced (1.3 fold increase; $\mathrm{p}=0.0004$ ) by PDGF-BB, which was inhibited in the presence of ATRA (19\% decrease; $p=0.0011$; fig. 6b).

\section{DISCUSSION}

MPM is an aggressive malignant tumour of mesothelial origin associated with asbestos exposure that has limited response to conventional chemotherapy and radiotherapy; the prognosis is very poor. Recently, the multi-targeted anti-folate pemetrexed has been approved as a first-line agent in combination with cisplatin for the treatment of MPM; however, overall survival remains very poor [19].

It has previously been reported that ATRA prevented both irradiation- and bleomycin-induced pulmonary fibrosis in mice by the inhibition of both IL-6-dependent proliferation and TGF- $\beta 1$-dependent transdifferentiation of lung fibroblasts. As MPM cells originate from mesenchymal cells similar to lung fibroblasts, here we examined the effect of ATRA on the progression of MPM tumour in SCID mice.

In the present study, we found that ATRA inhibited the proliferation of MPM cells but not mesothelial cells. Several factors, including IL-6, TGF- $\beta 1$ and PDGF, have been reported to be associated with MPM cells $[5,6,17,20]$. Here, we first examined whether the IL-6/IL-6R system also plays an important role in ATRA-mediated inhibition of MPM cell proliferation; however, in this study, ATRA had no effect on IL-6/IL-6R mRNA expression in MPM cells. 

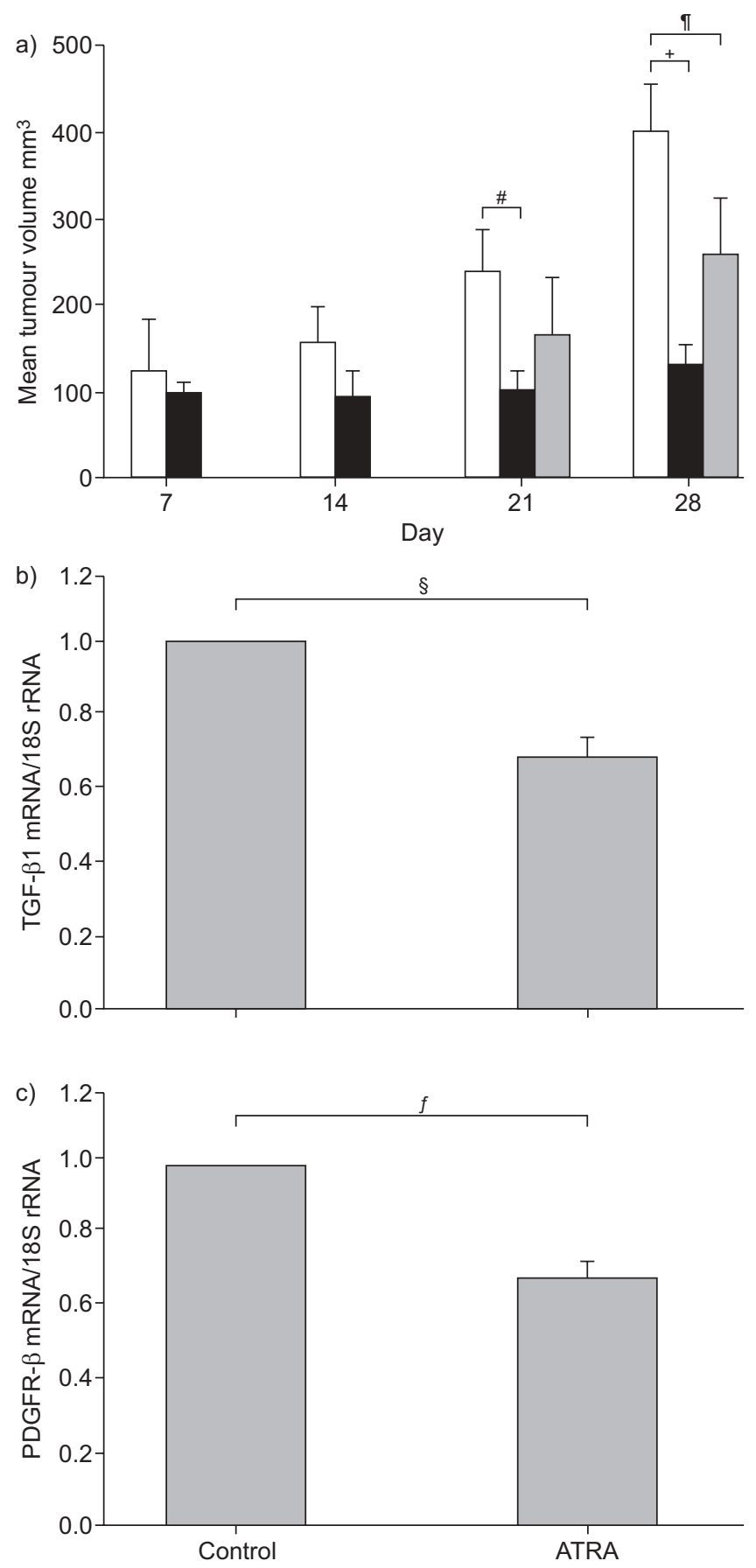

FIGURE 5. Antitumour efficacy with all-trans-retinoic acid (ATRA) in a subcutaneous xenograft model. MSTO-211H cells with a viability of $>95 \%$ were implanted subcutaneously into the back of SCID mice. a) The tumours were measured and their volume calculated in mice treated with vehicle control $(\square)$, treated i.p. with ATRA three times per week throughout the course (day 0-28; $\mathbf{a}$ ) or in the latter half of the period from inoculation to the end of the observation period (day 14-28; $\square$ ). b and c) Real-time reverse transcriptase PCR was performed to determine changes in mRNA levels in tumours for $b$ ) transforming growth factor (TGF)- $\beta 1$ and c) platelet-derived growth factor receptor (PDGFR) $-\beta$. The levels of mRNA are the ratio to $18 \mathrm{~S}$ ribosomal (r)RNA. The results are indicated as the mean $\pm S D$ of three separate experiments in triplicate. ${ }^{*}: p=0.0014 ;{ }^{\circ}: p=0.0011$; ${ }^{+}: p<0.0001 ;{ }^{\varsigma}$ : $p=0.0008 ;$ f: $p=0.0004$.
We then investigated the effect of ATRA on the production of TGF- $\beta 1$, another key cytokine in ATRA-mediated inhibition of pulmonary fibrosis, as we have previously demonstrated. We here showed that ATRA suppressed mRNA expression of both TGF- $\beta 1$ and TGF- $\beta 1 R$ in these cells and, moreover, inhibited TGF- $\beta 1$-dependent cell proliferation, suggesting that ATRA demonstrated the inhibitory effect on MPM cell proliferation via a TGF- $\beta 1$ /TGF- $\beta 1$ R autocrine mechanism. Generally, TGF- $\beta 1$ is produced by various normal cells observed surrounding MPM tissues, including fibroblasts, macrophages, neutrophils and lymphocytes [21, 22]. In vivo, therefore, in addition to the inhibitory effect of ATRA via the TGF- $\beta 1 /$ TGF- $\beta 1 R$ autocrine mechanism, ATRA could decrease MPM tumour progression via the TGF- $\beta 1$ /TGF- $\beta 1$ R paracrine loop by MPM cells and these TGF- $\beta 1$-producing surrounding cells. To determine the cellular mechanism in the regulation of TGF- $\beta 1$ production of MPM cells, we used some well characterised pharmacological inhibitors [23]. There are at least three distinct MAPK signal transduction pathways in mammalian cells that lead to activation of the ERK, JNK and p38MAPK pathways. As the induction of most cytokine genes requires the activation of NF$\kappa \mathrm{B}$, we next examined whether changes in NF- $\mathrm{kB}$ activity were involved in the suppressive effect of ATRA on TGF- $\beta 1$ expression in MPM cells, and found an important role of NF$\kappa \mathrm{B}$ in this process (fig. 3). These results suggest a possible mechanism whereby ATRA could reduce TGF- $\beta 1$ expression through an NF-kB-dependent pathway. Furthermore, it has been recently reported that the mechanism of asbestos-induced oncogenesis was associated with the activation of NF- $\mathrm{kB}$ [24], so the inhibitory effect of ATRA on NF- $\kappa$ B activation itself may be beneficial for the prevention of tumour growth in early MPM.

Next, we demonstrated in an in vivo study that i.p. administration of ATRA three times per week throughout the course greatly inhibited MPM tumour growth 28 days after inoculation. The administration of ATRA inhibited TGF- $\beta 1$ mRNA expression in grown MPM tumours in SCID mice. A recent study reported that TGF- $\beta 1$ was significantly associated with the growth of MPM cells in a murine MPM tumour model through TGF- $\beta 1$ /TGF- $\beta 1$ R systems and TGF- $\beta 1$ signalling [25], and our study appears to support this.

It is well known that cell migration plays a pivotal role in the disease progression of cancer. PDGF acts as two types of peptide, A $(16-\mathrm{kDa})$ and $\mathrm{B}(14-\mathrm{kDa})$ chains, with about $60 \%$ sequence identity, disulfide linked into three diametric molecules, PDGF-AA, -AB and -BB [26]. A and B chains bind to two cell-surface receptors: the $\alpha$ receptor can bind all three dimers (PDGF-AA, PDGF-AB and PDGF-BB) with high affinity and the $\beta$ receptor can only recognise PDGF-BB with high affinity and PDGF-AB with lower affinity [27]. It has been previously reported that MPM cells express PDGF- $\alpha$ and PDGF- $\beta$ mRNA, whereas no PDGF- $\beta$ and a low level of PDGF- $\alpha$ mRNA expression are detected in normal mesothelial cells. Moreover, PDGFR- $\beta$ mRNA expression is detected in MPM cells, whereas only PDGFR- $\alpha$ mRNA expression is observed in mesothelial cells [28]. In this study, we demonstrated that PDGFR- $\beta$ mRNA expression in MPM cells was inhibited by ATRA (fig. 6a), while ATRA had no effect on PDGF- $\beta$ mRNA expression (data not shown). Moreover, MPM cells migrated by PDGF-BB, which was suppressed by ATRA, as shown in figure 6b. PDGF-BB is also synthesised and 

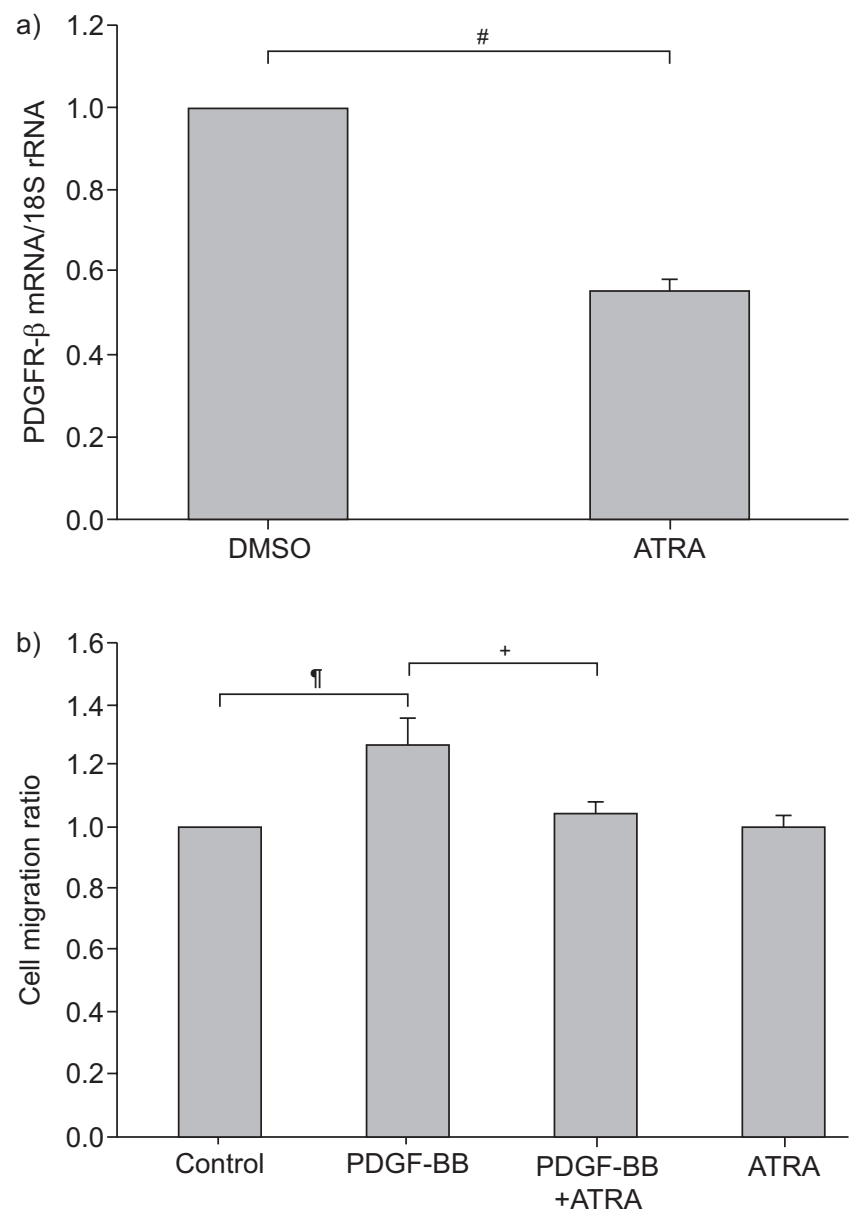

FIGURE 6. Inhibitory effect of all-trans-retinoic acid (ATRA) on platelet-derived growth factor (PDGF) receptor (PDGFR)- $\beta$ expression and PDGF-BB-induced migration of malignant pleural mesothelioma (MPM) cells. a) Real-time reverse transcription PCR was performed to determine changes in mRNA levels for PDGFR- $\beta$. MSTO-211H MPM cells were cultured in the presence or absence (dimethyl sulfoxide (DMSO) alone) of $10^{-5} \mathrm{M}$ of ATRA for $7 \mathrm{~h}$. The levels of mRNA for PDGFR- $\beta$ are the ratio to $18 \mathrm{~S}$ ribosomal (r)RNA, an endogenous control. The results are indicated as the mean $\pm S D$ of three separate experiments in triplicate. b) Cell migration assay. MSTO-211H cells were pre-cultured overnight with or without (DMSO alone) ATRA $\left(10^{-5} \mathrm{M}\right)$, and further cultured in the presence or absence of PDGF-BB $\left(10 \mathrm{ng} \cdot \mathrm{mL}^{-1}\right)$ with or without ATRA. The results are indicated as the mean \pm SD of three separate experiments in triplicate. ${ }^{\#}: p<0.0001 ; ": p=0.0004$; $+: p=0.0011$

released by several cells associated with MPM cells growth, such as fibroblasts, vascular smooth muscle cells and vascular endothelial cells [29]. The administration of ATRA had no effect on PDGF- $\beta$ mRNA expression in MPM tumour cells grown on SCID mice in the present study. However, the reduction of PDGFR- $\beta$ mRNA expression on MPM cells by ATRA may be estimated to inhibit the PDGF-BB/PDGFR- $\beta$ paracrine loop of MPM cells and PDGF-BB-producing surrounding cells, which might increase MPM cell migration and tumour invasion in cases of human MPM. As for cell migration, it has been reported that retinoic acid inhibited fibronectin and laminin synthesis and cell migration of human pleural mesothelioma in vitro [30].
DE CUPIS et al. [31] demonstrated that fenretinide (4HPR), a synthetic derivative of retinoic acid, induced apoptosis of the MPM cell line ZL34. However, in their report, 4HPR induced apoptosis not only of tumour cells but also of MeT-5A, SV40transformed normal mesothelial cells. Here, we demonstrate the selective inhibitory effect of ATRA on growth of MPM cells, but not of MeT-5A. By TUNEL assay, the increase of apoptosis was not observed in ATRA-treated MPM tumour cells in mice compared with untreated mice (data not shown). Next, we examined the mRNA expression of CYP26A1 [32], a retinoic acid regulated gene, by real-time RT-PCR, and found that mRNA levels of CYP26A1 were decreased in ATRAtreated MPM tumour cells in mice compared with untreated mice, which suggested an increased amount of active retinoic acid, namely, an autoregulation feedback loop (data not shown). However, it is not clear whether the observed effect is specific to retinoic acid signalling. Although the precise cellular mechanism has not been fully investigated, we propose the possibility that TGF- $\beta 1$ and PDGF receptors play an important role in this mouse model and ATRA prevents MPM cell growth through the inhibition of these cytokine/ cytokine receptor systems. Namely, we propose the dual inhibitory effect of ATRA on TGF- $\beta 1$-dependent proliferation and PDGF-BB-dependent migration of MPM cells, which may be the mechanism underlying the preventive and therapeutic effect of ATRA on MPM.

It is noteworthy that in this report we showed the "late", i.e. "therapeutic", effect of ATRA in MPM cell growth (fig. 5a) in addition to the "throughout", i.e. "preventive", effect, because in clinical use, the therapeutic effect is often more important when clinicians find that MPM is already progressive in their patients.

ATRA is known to affect cell differentiation, proliferation and development. Clinically, ATRA has been widely used in differentiation therapy for APL [33]. Furthermore, oral administration of the drug results in good compliance. Our data may lead to the development of novel strategies incorporating ATRA for the prevention and treatment of MPM.

\section{SUPPORT STATEMENT}

Funding for the present study was received from KAKENHI, Grant-inAid for Scientific Research (C) (20590936) and Special Coordination Funds for Promoting Science and Technology (H18-1-3-3-1) (both Tokyo, Japan).

\section{STATEMENT OF INTEREST}

None declared.

\section{ACKNOWLEDGEMENTS}

We thank R. Morimoto and H. Kitai for technical assistance (both Division of Respiratory Medicine, Dept of Internal Medicine, Hyogo College of Medicine, Nishinomiya, Japan).

\section{REFERENCES}

1 Wagner JC, Sleggs CA, Marchand P. Diffuse pleural mesothelioma and asbestos exposure in the North Western Cape Province. $\mathrm{Br} J$ Ind Med 1960; 17: 260-271.

2 Selikoff IJ, Hammond EC, Seidman H. Latency of asbestos disease among insulation workers in the United States and Canada. Cancer 1980; 15: 2736-2740. 
3 Nowak AK, Lake RA, Kindler HL, et al. New approaches for mesothelioma: biologics, vaccines, gene therapy, and other novel agents. Semin Oncol 2002; 29: 82-96.

4 Sterman DH, Kaiser LR, Albelda SM. Advances in the treatment of malignant pleural mesothelioma. Chest 1999; 116: 504-520.

5 Adachi Y, Aoki C, Yoshio-Hoshino N, et al. Interleukin-6 induces both cell growth and VEGF production in malignant mesotheliomas. Int J Cancer 2006; 119: 1303-1311.

6 Jagadeeswaran R, Ma PC, Seiwert TY, et al. Functional analysis of c-Met/hepatocyte growth factor pathway in malignant pleural mesothelioma. Cancer Res 2006; 66: 352-361.

7 Dubois C, Schlageter MH, de Gentile A, et al. Modulation of IL-8, IL-1 $\beta$, and G-CSF secretion by all-trans retinoic acid in acute promyelocytic leukemia. Leukemia 1994; 8: 1750-1757.

8 Maeno T, Tanaka T, Sando Y, et al. Stimulation of vascular endothelial growth factor gene transcription by all trans retinoic acid through Sp1 and Sp3 sites in human bronchioloalveolar carcinoma cells. Am J Respir Cell Mol Biol 2002; 26: 246-253.

9 Pelicano L, Li F, Schindler C, et al. Retinoic acid enhances the expression of interferon-induced proteins: evidence for multiple mechanisms of action. Oncogene 1997; 15: 2349-2359.

10 Ogata A, Nishimoto N, Shima Y, et al. Inhibitory effect of all-trans retinoic acid on the growth of freshly isolated myeloma cells via interference with interleukin-6 signal transduction. Blood 1994; 84: 3040-3046.

11 Sidell N, Taga T, Hirano T, et al. Retinoic acid-induced growth inhibition of a human myeloma cell line via down-regulation of IL-6 receptors. J Immunol 1991; 146: 3809-3814.

12 Tabata C, Kubo H, Tabata R, et al. All-trans retinoic acid modulates radiation-induced proliferation of lung fibroblasts via IL-6/IL-6R system. Am J Physiol Lung Cell Mol Physiol 2006; 290: 597-606.

13 Tabata C, Kadokawa Y, Tabata R, et al. All-trans-retinoic acid prevents radiation- or bleomycin-induced pulmonary fibrosis. Am J Respir Crit Care Med 2006; 174: 1352-1360.

14 Jang BC, Jung TY, Paik JH, et al. Tetradecanoyl phorbol acetate induces expression of Toll-like receptor 2 in U937 cells: involvement of PKC, ERK, and NF-кB. Biochem Biophys Res Commun 2005; 328: 70-77.

15 Lee KY, Ito K, Hayashi R, et al. NF- $\mathrm{KB}$ and activator protein 1 response elements and the role of histone modifications in IL-1 $\beta$ induced TGF- $\beta 1$ gene transcription. J Immunol 2006; 176: 603-615.

16 Fritz DK, Kerr C, Tong L, et al. Oncostatin-M up-regulates VCAM-1 and synergizes with IL-4 in eotaxin expression: involvement of STAT6. J Immunol 2006; 176: 4352-4360.

17 Versnel MA, Claesson-Welsh L, Hammacher A, et al. Human malignant mesothelioma cell lines express PDGF $\beta$-receptors whereas cultured normal mesothelial cells express predominantly PDGF $\alpha$-receptors. Oncogene 1991; 6: 2005-2011.

18 Ross R, Raines EW, Bowen-Pope DF. The biology of plateletderived growth factor. Cell 1986; 46: 155-169.

19 Vogelzang NJ, Rusthoven JJ, Symanowski J, et al. Phase III study of pemetrexed in combination with cisplatin versus cisplatin alone in patients with malignant pleural mesothelioma. J Clin Oncol 2003; 21: $2636-2644$
20 Gerwin BI, Lechner JF, Reddel RR, et al. Comparison of production of transforming growth factor- $\beta$ and platelet-derived growth factor by normal human mesothelial cells and mesothelioma cell lines. Cancer Res 1987; 47: 6180-6184.

21 Noble PW, Henson PM, Lucas C, et al. Transforming growth factor- $\beta$ primes macrophages to express inflammatory gene products in response to particulate stimuli by an autocrine/ paracrine mechanism. J Immunol 1993; 151: 979-989.

22 Derynck R, Jarrett JA, Chen EY, et al. Human transforming growth factor- $\beta$ complementary DNA sequence and expression in normal and transformed cells. Nature 1985; 316: 701-705.

23 Sullivan DE, Ferris M, Pociask D, et al. Tumor necrosis factor- $\alpha$ induces transforming growth factor- $\beta 1$ expression in lung fibroblasts through the extracellular signal-regulated kinase pathway. Am J Respir Cell Mol Biol 2005; 32: 342-349.

24 Yang H, Bocchetta M, Kroczynska B, et al. TNF- $\alpha$ inhibits asbestosinduced cytotoxicity via a NF-кB-dependent pathway, a possible mechanism for asbestos-induced oncogenesis. Proc Natl Acad Sci USA 2006; 103: 10397-10402.

25 Suzuki E, Kim S, Cheung HK, et al. A novel small-molecule inhibitor of transforming growth factor $\beta$ type I receptor kinase (SM16) inhibits murine mesothelioma tumor growth in vivo and prevents tumor recurrence after surgical resection. Cancer Res 2007; 67: 2351-2359.

26 Betsholtz $\mathrm{C}$, Johnsson $\mathrm{A}$, Heldin $\mathrm{CH}$, et al. cDNA sequence and chromosomal localization of human platelet-derived growth factor A-chain and its expression in tumour cell lines. Nature 1986; 320: 695-699.

27 Eriksson A, Siegbahn A, Westermark B, et al. PDGF $\alpha$ - and $\beta$ receptors activate unique and common signal transduction pathways. EMBO J 1992; 11: 543-550.

28 Langerak AW, De Laat PA, Van Der Linden-Van Beurden CA, et al. Expression of platelet-derived growth factor (PDGF) and PDGF receptors in human malignant mesothelioma in vitro and in vivo. J Pathol 1996; 178: 151-160.

29 Heldin $\mathrm{CH}$, Westermark B. Mechanism of action and in vivo role of platelet-derived growth factor. Physiol Rev 1999; 79: 1283-1316.

30 Scarpa S, Giuffrida A, Palumbo C, et al. Retinoic acid inhibits fibronectin and laminin synthesis and cell migration of human pleural mesothelioma in vitro. Oncol Rep 2002; 9: 205-209.

31 de Cupis A, Semino C, Pirani P, et al. Enhanced effectiveness of last generation antiblastic compounds vs. cisplatin on malignant pleural mesothelioma cell lines. Eur J Pharmacol 2003; 473: 83-95.

32 Quere R, Baudet A, Cassinat B, et al. Pharmacogenomic analysis of acute promyelocytic leukemia cells highlights CYP26 cytochrome metabolism in differential all-trans retinoic acid sensitivity. Blood 2007; 109: 4450-4460.

33 Chen SJ, Zhu YJ, Tong JH, et al. Rearrangements in the second intron of the RARA gene are present in a large majority of patients with acute promyelocytic leukemia and are used as molecular marker for retinoic acid-induced leukemic cell differentiation. Blood 1991; 78: 2696-2701. 